\section{(2) OPEN ACCESS}

\title{
Potentials and pitfalls of including pharmacies as youth-friendly contraception providers in low- and middle-income countries
}

\author{
Lianne Gonsalves (10 , 1,2,3 Adriane Martin Hilber, ${ }^{2,3}$ Kaspar Wyss, $^{2,3}$ \\ Lale Say ${ }^{1}$
}

\begin{abstract}
'Department of Sexual and Reproductive Health and Research including UNDP/ UNFPA/UNICEF/WHO/World Bank Special Programme of Research, Development and Research Training in Human Reproduction (HRP), World Health Organization, Geneva, Switzerland

${ }^{2}$ Swiss Centre for International Health, Swiss Tropical and Public Health Institute, Basel, Switzerland

${ }^{3}$ University of Basel, Basel, Switzerland
\end{abstract}

\section{Correspondence to} Lianne Gonsalves, Department of Sexual and Reproductive Health and Research including UNDP/UNFPA/UNICEF/WHO/ World Bank Special Programme of Research, Development and Research Training in Human Reproduction (HRP), World Health Organization, Geneva, Switzerland; liannemg@gmail. com

Received 17 March 2020 Revised 3 June 2020 Accepted 10 June 2020 Published Online First 11 August 2020

\section{Check for updates}

(C) World Health Organization 2021. Licensee BMJ.

To cite: Gonsalves L, Martin Hilber A, Wyss K, et al. BMJ Sex Reprod Health 2021;47:6-8.

\section{PHARMACIES ENABLING YOUTH \\ 'SELF-CARE' IN SEXUAL AND REPRODUCTIVE HEALTH}

Older adolescents and young adults between the ages of 15-24 years (collectively termed 'youth') face a variety of barriers when trying to access sexual and reproductive health (SRH) services - particularly contraceptive services - from health facilities. ${ }^{1}$ Policy restrictions and community norms which deem youth access 'inappropriate' can dissuade young people from going to a facility. Those who do go often encounter 'unfriendly' staff, and facilities with inconvenient opening hours or a lack of confidentiality and privacy. ${ }^{1}$

In recent years, evidence on the safety and efficacy of contraceptives, coupled with global commitments by countries and donors to address health systems barriers and expand access to contraception (eg, Family Planning 2020²), have resulted in key services and products being made available outside of health facilities. ${ }^{3}$ As a result, certain contraceptive products, including emergency contraception and daily contraceptive pills, are now available through retail pharmacies and drug shops (lower-tier establishments which do not employ a trained pharmacist, and are limited in the drugs they can dispense $\left.{ }^{4}\right) .{ }^{5}$ Additionally, the recent advance of self-administered injectable contraception reflects a trend towards broader 'self-care' (individuals addressing their own health needs, with or without the support of a healthcare provider) and user autonomy in accessing and using modern contraceptive methods. ${ }^{67}$
Pharmacies and drug shops, therefore, could be considered an important alternate contraception source for young people, especially in low- and middleincome countries (LMICs). ${ }^{4}$ Yet they are not uniformly lauded as a panacea to meet young people's need for contraception. The breadth of contraception available in many pharmacies remains narrow. Also, many LMICs struggle with variable service quality and illegal pharmacy activity, including unregistered premises, untrained personnel and/or substandard commodities. So, to what extent can pharmacies and drug shops be a quality catalyst for empowering a young population around their SRH?

\section{'YOUTH-FRIENDLY ENOUGH' - PHARMACIES AS CONTRACEPTION PROVIDERS TO YOUNG PEOPLE}

Service provision to young people in general can be assessed by five tenets of quality, or adolescent/youth-"friendliness": accessibility, acceptability, appropriateness, effectiveness and equity. ${ }^{8}$ From a programming perspective, all five qualities must be present to ensure quality services are available to all young people who need them. However, studies which have explored young people's access to contraception services through pharmacies indicate that these standards may not be equally valued by young users.

Appropriateness (ensuring the right health services are provided) and effectiveness (ensuring the right services are delivered in the correct manner) are essential for health programmers and governments. However, young people encountering individual, family and/ 
or community resistance related to sexual activity value confidentiality and respectful treatment (both of which are elements of acceptability). ${ }^{8}$ It is unsurprising, therefore, that pharmacy services are also appreciated for their acceptability and accessibility: non-judgmental personnel (in certain settings), privacy (in certain settings), convenient locations and proximity, opening hours, speed of service and ease of access. ${ }^{9}$ As a result, young people seek support from pharmacies and drug shops, even where there are concerns about service appropriateness, effectiveness or cost. Put simply, young pharmacy customers prioritise a narrower set of 'quality' standards than health programmers or policymakers.

\section{ATTENTION TO EQUITY - FINANCING CONTRACEPTION SERVICES IN PHARMACIES}

Pharmacy personnel providing contraception services and broader support for 'self-care' brings contraception closer to users of all ages. Additionally, 'selfcare' has generated enthusiasm for its potential to improve the cost-effectiveness of delivering SRH interventions. For pharmacy interventions, however, financing concerns remain: pharmacy services in many countries, particularly in LMICs, are often paid for out-of-pocket (a non-reimbursed, direct payment by the individual).

As identified by Remme and colleagues, ${ }^{10}$ evidence on how self-care interventions are financed is lacking, and with it insights into the equity (or lack thereof) of these interventions. For young customers, pharmacy access seems important, yet is it only well-off young people and those living in urban areas who take advantage of these services?

Our own research in peri-urban Coastal Kenya found young people reported contraception purchased at a pharmacy to be 'cheaper' than going to a health facility. Transport expenses, waiting time, and payment for provider-ordered tests made 'free' contraception services at public facilities surprisingly costly. ${ }^{11}$ However, even in settings where pharmacy purchases are objectively more expensive, we posit that, with the exception of the very poorest, young users with less access to money will elect to absorb this financial cost. For them, contraceptives purchased from private sources may still be less 'costly' than the financial and especially the non-financial costs of travelling to and being seen accessing services in a public health facility. Young users, therefore, may appear willing to shoulder the out-of-pocket cost of contraception in pharmacies, while still being disproportionately burdened (as compared with adults) by the expense.

Research to understand young people's willingness to pay and their sources of income is needed, especially given that this population group is likely to be financially dependent on other household members. As contraceptive services are shared to private retail pharmacies, we urge caution to ensure that disproportionate financial burden does not shift to the consumer, even those groups who appear to be enthusiastic adopters.

\section{REACHING 'QUALITY' YOUTH-FRIENDLY HEALTH SERVICES IN PHARMACIES}

The enthusiasm for self-care as it relates to contraception services and the role that pharmacies can play is not unwarranted. In many countries, private pharmacies are already an integral part of the network of providers relied on by young people. Nonetheless, there is still much to be done to improve the current provision of contraception services to young people in pharmacies and drug shops around the world. As such, we agree with Narasimhan and colleagues' assertion that 'self-care' (provided through pharmacies or otherwise) is not a 'shortcut' for countries to achieve universal health coverage. ${ }^{12}$

Making additional contraception services available in pharmacies cannot come without improved regulation and control of pharmacy services as well as multisectoral efforts to improve demand for and delivery of quality services. Providing contraception through pharmacies can overcome important barriers to accessibility and acceptability for young people. It does not, however, absolve the health system and governments of their responsibility to ensure young people are receiving appropriate and effective and affordable contraceptive services.

Twitter Lianne Gonsalves @liannegonsalves

Acknowledgements The authors appreciate the technical contributions of Dr Veloshnee Govender.

Contributors LG developed the draft manuscript, with assistance from LS. All authors provided extensive edits of drafts.

Funding The authors have not declared a specific grant for this research from any funding agency in the public, commercial or not-for-profit sectors.

Disclaimer LG and LS are staff members of the World Health Organization. The authors alone are responsible for the views expressed in this publication and they do not necessarily represent the views, decisions or policies of the World Health Organization.

Competing interests None declared.

Patient and public involvement Patients and/or the public were not involved in the design, or conduct, or reporting, or dissemination plans of this research.

Patient consent for publication Not required.

Provenance and peer review Not commissioned; externally peer reviewed.

Open access This is an open access article distributed under the terms of the Creative Commons Attribution-Non commercial IGO License (CC BY-NC 3.0 IGO), which permits use, distribution, and reproduction for non-commercial purposes in any medium, provided the original work is properly cited. In any reproduction of this article there should not be any suggestion that $\mathrm{WHO}$ or this article endorse any specific organization or products. The use of the WHO logo is not 


\section{Editorial}

permitted. This notice should be preserved along with the article's original URL..

\section{ORCID iD}

Lianne Gonsalves http://orcid.org/0000-0003-2409-5043

\section{REFERENCES}

1 High-Impact Practices in Family Planning (HIP). Adolescentfriendly contraceptive services: mainstreaming adolescentfriendly elements into existing contraceptive services. Washington DC, United States: USAID, 2015.

2 Family Planning 2020. FP2020 overview, 2020. Available: https://www.familyplanning2020.org/about-us

3 World Health Organization. Task sharing to improve access to family planning/contraception: summary brief. Geneva, Switzerland: World Health Organization, 2017.

4 High-Impact Practices in Family Planning (HIP). Drug shops and pharmacies: sources for family planning commodities and information. Washington DC, United States: USAID, 2013.

5 World Health Organization. Family planning evidence brief - partnering with the private sector to strengthen provision of contraception. Geneva, Switzerland: World Health Organization, 2017.
6 World Health Organization. WHO consolidated guideline on self-care interventions for health: sexual and reproductive health and rights. Geneva, Switzerland: World Health Organization, 2019.

7 Kennedy CE, Yeh PT, Gaffield ML, et al. Self-administration of injectable contraception: a systematic review and meta-analysis. BMJ Glob Health 2019;4:e001350.

8 World Health Organization. Making health services adolescent friendly: developing national quality standards for adolescent friendly health services. Geneva, Switzerland: World Health Organization, 2012.

9 Gonsalves L, Hindin MJ. Pharmacy provision of sexual and reproductive health commodities to young people: a systematic literature review and synthesis of the evidence. Contraception 2017;95:339-63.

10 Remme M, Narasimhan M, Wilson D, et al. Self care interventions for sexual and reproductive health and rights: costs, benefits, and financing. BMJ 2019;365:11228.

11 Gonsalves L, Wyss K, Cresswell JA, et al. Mixed-methods study on pharmacies as contraception providers to Kenyan young people: who uses them and why? BMJ Open 2020;10:e034769.

12 Narasimhan M, de Iongh A, Askew I, et al. It's time to recognise self care as an integral component of health systems. BMJ 2019;365:11403. 